\title{
氮化碳薄膜的制备及 $\mathrm{C}-\mathrm{N} / \mathrm{CuInSe} \mathrm{Se}_{2} / \mathrm{Si}$ 异质结光伏特性
}

\author{
周之斌 \\ 崔容强* \\ (安徽师范大学物理系. 芜湖 241000) \\ (西安交通大学太阳能研究所, 西安 710049)
}

\section{关键词氮化碳薄膜 $\mathrm{C}-\mathrm{N} / \mathrm{CuInSe}$ 异质结 光伏特性}

新材料棃化碳薄膜具有超强硬度和独特的物理、化学性质. 近年来, 引起国内、外学者的重 视, 1989 年, $\mathrm{Liu}$ 等 ${ }^{[1]}$ 从理论上预测人工合成具有 $\beta-C_{3} \mathrm{~N}_{4}$ 结构的氮化碳材料的可能性, 该材料 有很大体变模量 $\mathrm{B}$, 使其具有超强硬度等特性, 极有可能在光电、磁、机械工业等领域获重要的 应用, 但合成工艺上一直没有取得突破 ${ }^{[23}$, 直到 1993 年, 美国哈佛大学 $\mathrm{Niu}$ 等报道采用激光 束蒸发石墨加氮离子束源工艺合成出氮化碳薄膜 ${ }^{[4]}$, 该方法回避了等离子工艺过程的热动力 学平衡及限制, 显然只可作为人工合成预测的新材料的原理性方法而无法实用. 我们从 1988 年开始这项相关研究, 同年合成出氮化碳薄膜, 采用的工艺是射频溅射石墨靶, 峑、氮作为反 应、浌射气体; 合成的氮化碳薄膜与 $\mathrm{CuInSe} \mathrm{e}_{2}$ 薄膜匹配构成 $\mathrm{C}-\mathrm{N} / \mathrm{CuInSe} \mathrm{e}_{2}$ 异质结, 成功地获得该 结构的薄膜太阳能电池初步参数. 这一工作, 为进一步开展氮化碳薄膜材料合成、及固体结构 理论、物理特性等基础研究, 以及在光伏器件上应用展示出动人的前景.

\section{1 材料及工艺}

\section{1 射频浌射法沉积攻化碳薄膜}

实验装置的主要部分如图 1 所示, 选用高 纯石墨片做成 $\varnothing 100 \mathrm{~mm}$ 靶, 用银导电胶粘贴 到靶托电极上, 选用 $(100)$ 单晶硅片和玻璃作衬 底, 先对衬底作机械抛光和丙酮、甲醇超声清 洗; 典型工艺条件如表 1 .

表 1 沉积氮化碳薄膜工艺参数

\begin{tabular}{|c|c|c|c|c|}
\hline 反应、涹射 & 氮气 & $0.3 \sim 0.8 \mathrm{~Pa}$ & 靶距 & $90 \mathrm{~mm}$ \\
\hline 气体压强 & 氞气 & $0.5 \mathrm{~Pa}$ & 浌射电压 & $2.0 \mathrm{kV}$ \\
\hline 祄底温度 & & $300^{\circ} \mathrm{C}$ & 沉积速率 & $8.3 \mathrm{~nm} / \mathrm{min}$ \\
\hline
\end{tabular}

1995-03-24 收稿, 1995-06-10 收修改稿

* 现在地址:国家经委海南新能源办公室,海口 570003

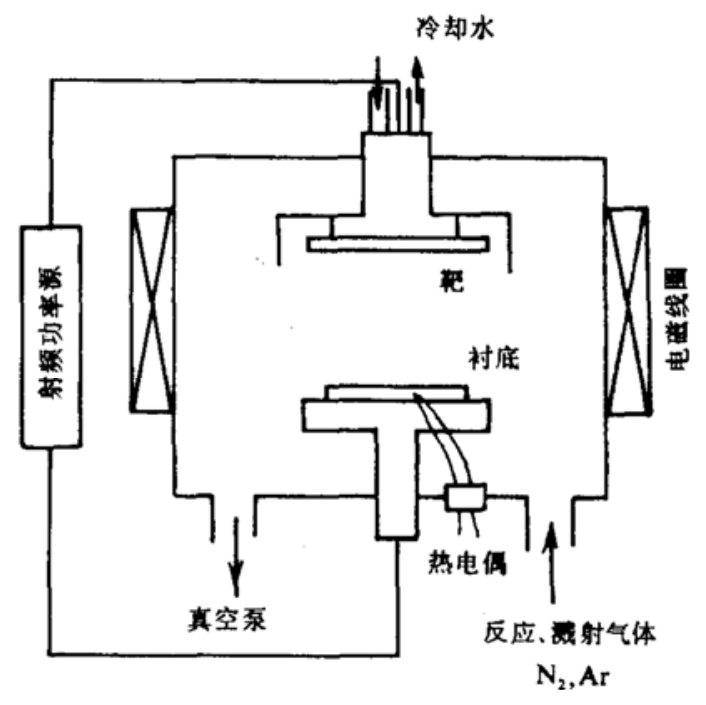

图 1 射频浅射工艺装置主要部分示意图 


\section{2 射频沷射制备 $\mathrm{CuInSe} 2$ 薄膜}

选用高纯 $\mathrm{Cu} 、 \mathrm{Se}$ 粉末和 In 箔片, 先将 $\mathrm{Cu} 、 \mathrm{Se}$ 粉末按 $2: 1$ 比例混合均匀, 球磨数小时, 冷 压成形, 在氮气氛保护下烧结成合金, 再用银导电胶将 In 箔片均匀对称地粘贴到合金靶上, 通 过改变 In 箔片的覆盖面积和浌射工艺条件可有效地控制沉积膜的成分比. 该实验的工艺条

表 $2 \mathrm{CuInSe}_{2}$ 薄膜沉积工艺参数

\begin{tabular}{cccc}
\hline 昰气气发 & $0.2 \sim 0.4 \mathrm{~Pa}$ & 射频电压 & $1.4 \sim 2.4 \mathrm{kV}$ \\
\hline 衬底温度 & $350^{\circ} \mathrm{C}$ & 沉积速率 & $4.4 \mathrm{~nm} / \mathrm{min}$ \\
慗距 & $110 \mathrm{~mm}$ & & \\
\hline
\end{tabular}

件如表 2.

选用 $\mathrm{P}^{+}$型导电 $2.5 \sim 5 \Omega \mathrm{cm}$ 硅单晶片 $(100)$ 为衬底, 依次沉积两材料, 构成 $\mathrm{C}-\mathrm{N} / \mathrm{CuInSe} / 2 \mathrm{Si}$ 异质结.

\section{2 测试与讨论}

\section{1 膜成分、结构及电学特性}

由俄歇 (Auger) 电子能谱分析知, 氮化碳薄膜中氮原子平均含量为 $28 \%$, 如图 2, 工作气 体中氮的比例以及贼射电压和功率是控制膜中氮含量的关键, 同时, 维持一定比例的氩气对 稳定辉光放电、沉积优质均匀膜是有利的.

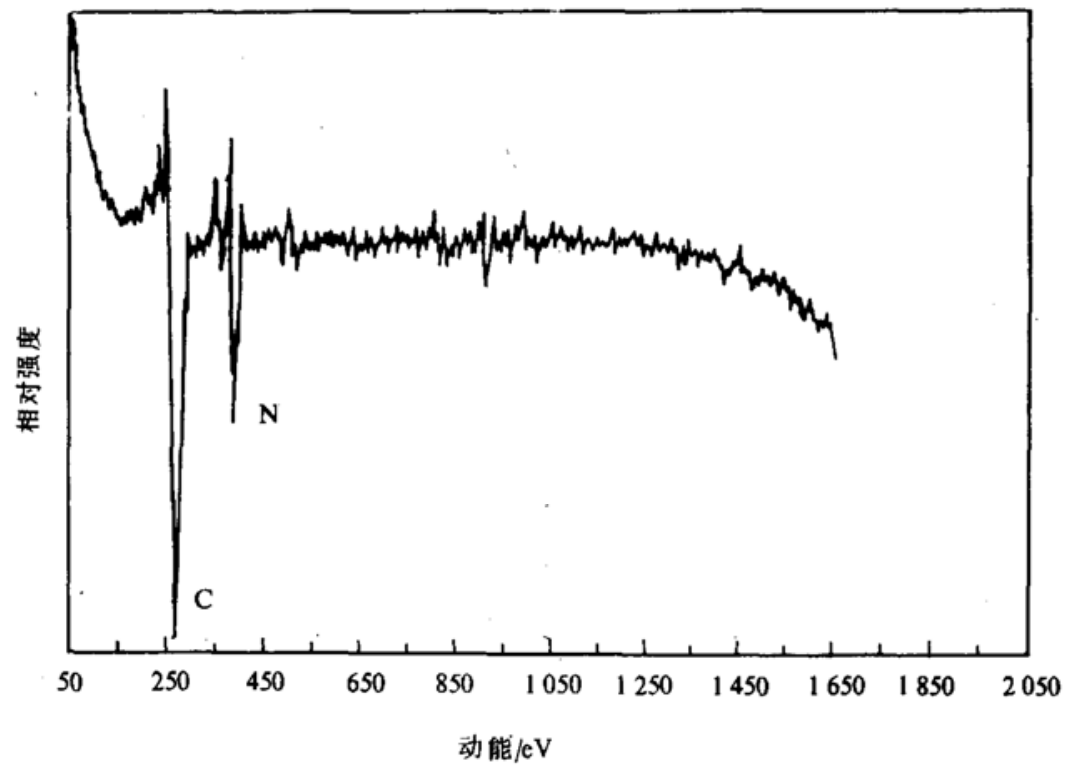

图 2 氮化碳薄膜俄歇 (Auger) 电子能谱 无素组成: $C$ 为 $67 \%, N$ 为 $28 \%$, 其它为 $5 \%$

由扫描和透射电子显微镜分析可知, 该工艺沉积的氮化碳薄膜是以非晶为主的晶化、非晶 复相态结构, 有少量较大颗粒结晶, 线径在 $2 \sim 5 \mu \mathrm{m}$, 其外形近多面体; 有一些是结晶粒的连 体, 形成一族晶粒, 如图 3 所示; 从选区电子衍射点阵分析知, 这些结晶颗粒不可能为石墨或 金刚石结晶 (如图 4), 对其计算知, 对应衍射斑点的各晶面组间隔为 $d: 2.21,2.11,1.24,1.19$, $1.07,0.80$ 与 $\mathrm{Liu}^{[(1)}$ 理论上预测的 $\beta-\mathrm{C}_{3} \mathrm{~N}_{4}$ 结构电子衍射平面间隔 $d: 2.20,2.11,1.27,1.20$, $1.09,0.80$, 基本相符, 它们分别对应于唱面: (101), (210), (320), (002), (411), (611), 由此可确知, 这些微粒为 $\beta-C_{3} N_{4}$ 结唱, 在图 4 中, 也可观察到非晶结构的衍射晕圈.

最近, $\mathrm{Li}$ 等报道采用直流浌射法获得非晶和晶态混合膜 ${ }^{[2]}$, 但不是 $\beta-\mathrm{C}_{3} \mathrm{~N}_{4}$ 结晶; 而 


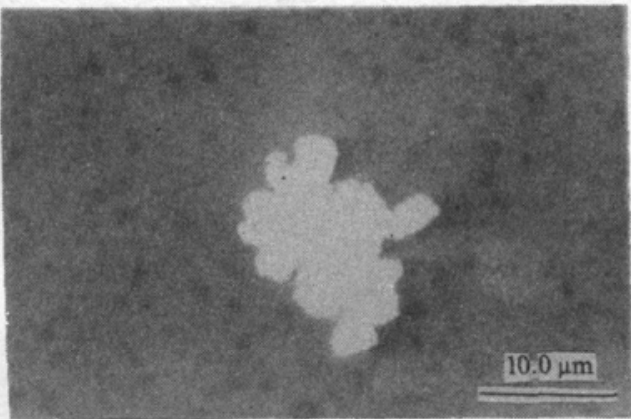

图 3 氮化碳薄膜 SEM 形貌

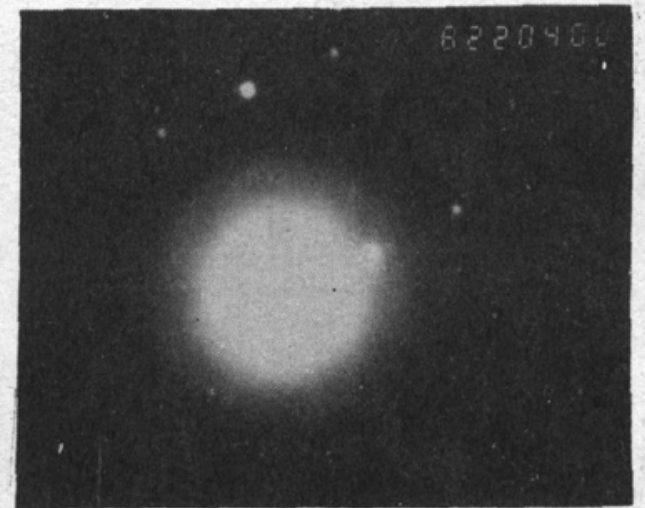

图 4 氮化碳薄膜电子束衍射点阵 非晶衍射量圈和 $\beta-C_{3} N_{4}$ 衍射斑点组成

Nakayama ${ }^{[3]}$ 采用射频磁控溅射法只得到非晶态膜, 他们认为非晶态的氮化碳 $\mathrm{C}-\mathrm{N}$ 键是类似 于 $\beta-\mathrm{C}_{3} \mathrm{~N}_{4}$ 网络结构的共价键. 我们的工作是射频浌射法合成 $\beta-\mathrm{C}_{3} \mathrm{~N}_{4}$ 结构的实验实现.

我们又对该薄膜材料做了电学性质的测定,一般来说, 材料的电学性质决定于非晶态的短 程有序结构, 该氮化碳薄膜的电学特性依然受占主要部分的非晶态性质决定, 碳与氮以短的 共价键结合, 非晶态中氮原子的五个外层电子没有充分与碳原子成键, 未成键的电子对材料 的导电性起重要作用, 由四探针法测知沉积的氮化碳薄膜为 $\mathrm{n}$ 型导电、电阻率为 $10^{2} \sim 10^{3} \Omega \mathrm{cm}$ 的半导体.

同样, 采用俄歇电子能谱分析硒铟铜薄膜的成分, Cu、 In、Se 原子数百分比约为 $1: 1: 2$, 略 富硒 (如图 5), 这样的工艺条件下获得的硒铟铜膜, 它的富硒原子在价带上形成受主空穴能 级, 即硒的自由空穴, 膜显 $\mathrm{p}$ 型导电 ${ }^{[s]}$, 其电阻率为 $10^{-2} \sim 10^{2} \Omega \mathrm{cm}$, 可由工艺控制.

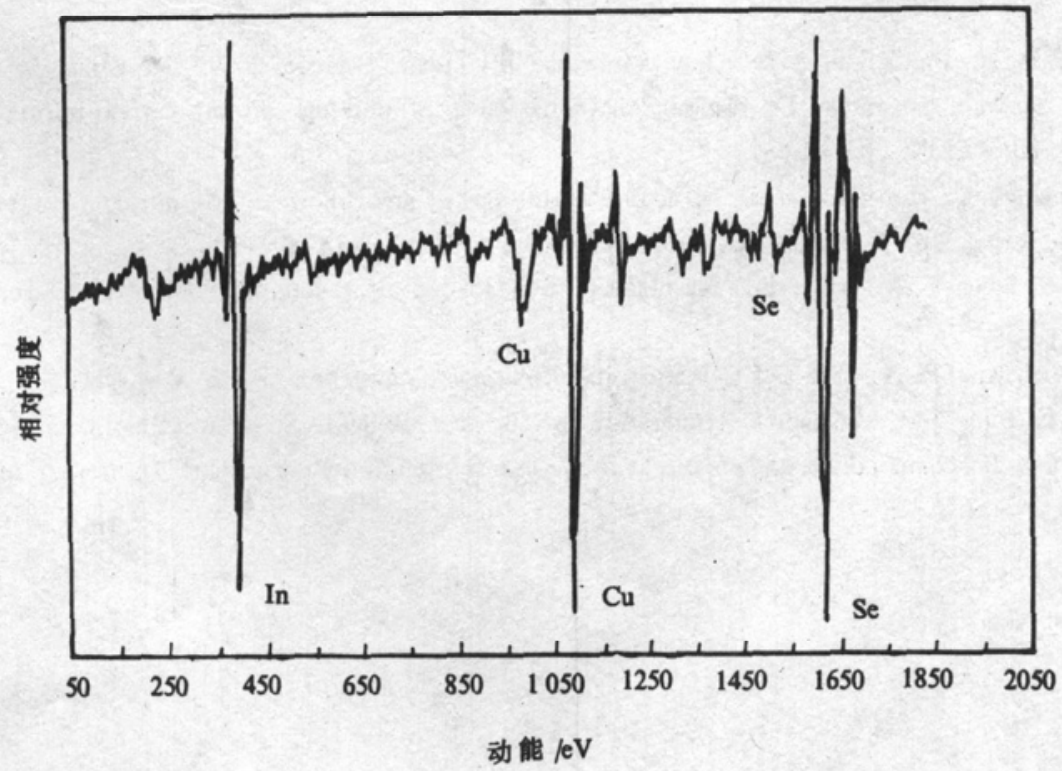

图 5 硒钢铜薄膜俄歇电子能谱

元素组成: $\mathrm{Cu}$ 为 $23 \%, \mathrm{In}$ 为 $22 \%, \mathrm{Se}$ 为 $48 \%$, 其它为 $7 \%$ 


\section{$2.2 \mathrm{C}-\mathrm{N} / \mathrm{CuInSe}_{2} / \mathrm{Si}$ 异质结}

$\mathrm{CuInSe} \mathrm{n}_{2}$ 材料可见光吸收谱与太阳光谱配合较好, 为优良的光电材料, 曾报道 $\mathrm{CdS} / \mathrm{CuInSe}{ }_{2}$ 薄膜太阳能电池光电转换效率达到 $11 \%{ }^{[6]}$, 但该器作稳定性差, 主要原因是 $\mathrm{CdS}$ 薄膜易受潮气 侵蚀, 在膜内及 $\mathrm{Pn}$ 结区形成复合中心。非旵氮化碳膜的禁带宽度约为 $1.2 \sim 1.5 \mathrm{eV}^{17}$, 与禁带 宽度为 $1.0 \mathrm{eV}$ 的 $\mathrm{CuInSe} \mathrm{e}_{2}$ 构成异质结配合适中, $\beta-\mathrm{C}_{3} \mathrm{~N}_{4}$ 虽然与 $\mathrm{CuInSe}_{2}$ 晶格和键长失配, 但非 晶态的氮化碳可消减失配造成的异质膜界面缺陷对光电子的复合 $\left(\mathrm{C}-\mathrm{N}, \mathrm{CuInSe}_{2}\right.$ 的键长分别 为 0.147 和 $0.24 \mathrm{~nm}^{[4.57)}$, 非晶膜也不存在多唱膜中的品面缺陷. 这样构成的异质结质量优 良, 在 $\mathrm{AM} 1.5,100 \mathrm{~mW} / \mathrm{cm}^{2}$ 光照下, 开路电压 $V_{\mathrm{oc}}$ 达 $450 \mathrm{mV}$, 短路电流密度 $I_{\mathrm{sc}}$ 为 $2 \mathrm{~mA} / \mathrm{cm}^{2}$, 我们也测试了 $\mathrm{CuInSe}_{2} / \mathrm{Si} \mathrm{pp}^{+}$高低结的开路电压为 $40 \mathrm{mV}$, 可以认为 $V_{\mathrm{cc}}$ 主要是由 $\mathrm{C}-\mathrm{N} /$ CuInSe $e_{2}$ 异质结形成。放置于湿度约 $90 \%$ 的空会中, 间隔二个月后, 再次测试, 开路电坐没有 衰减, 可无, 氮化碳膜的密实和高强度性质对异质结形成保护.

\section{3 结论与分析}

在氮、氩气氛中射频溅射石墨靶 $\mathrm{T}$. 㠩, 可合成出镶访有 $\beta-\mathrm{C}_{3} \mathrm{~N}_{4}$ 结构微粒的结旵、非唱复合 态的氮化碳薄膜。通过进一步深人研究等离子体工艺及改进热动力学平衡和限制, 获得高奛 化程度的多唱膜, 提高膜中氮的含量是完全可行的.

该材料可在光电子器件中㢸得应用, 是否存在与氮化碳唱格配合更适宜的光电材料, 以及 选择近合功函数的金属作电极, 提高光生电流收集效率有待进一步研究.

致谢 参加部分调研和样品测试工作的先后还有: 卢一民、董光能(西安) 和刘付轶 (芜 湖) 等同志, 特致谢意.

\section{参考 文 献}

I Liu $\wedge$ Y, Cohen M L. Prediction of new low compressibility solids. Science, 1989, 245: 841

2 Li Dong, Chung Yipwah, Sproul W D. Nano-indentation studies of ultrahigh strenth carbon nitride thin films. J Appl Phys, 1993, 74(1): 219 223

3 Nakayama N, Tsuchiya Y, Tamada $\mathrm{S}$ et al. Structural properties of amorphous carbon nitride films prepared by reative RF-magnetron sputtering. Jpn J Appl Phys, 1993, 32(10A): I 405 1468

4 Niu C, Lu Y Z. Lieher C M. Experimental realization of the covalent solid carbon nitride. Science, 1993, 261(16): $334 \sim 337$

5 I

6 Hollingsworth R F, Sites J R. Annealing temperature effects on CuInSe/CdS. Solar Cells, 1986, 16:457 477

7 Savvides N, Window B. Diamondlike amorphous carbon films prepared by magnetron sputtering of graphite. J Vac Sci Technol, 1985, A3(6): $2386 \sim 2390$ 